\title{
Text Mining of English Picture Books
}

\author{
Hiromi Ban \\ Graduate School of Nagaoka University of Technology \\ 1603-1 Kamitomiokamachi, Nagaoka, Niigata \\ 940-2188, Japan \\ (+81) 258-47-9803 \\ je9xvp@yahoo.co.jp
}

\author{
Takashi Oyabu \\ NIHONKAI International Exchange Center \\ 2-31 Toiyamachi, Kanazawa, Ishikawa \\ 920-0061, Japan \\ (+81) 76-231-7413 \\ oyabu24@gmail.com
}

\begin{abstract}
Picture books play an important role as a material that develops children's linguistic competence. Thus, English picture books can be considered to be indispensable in children's English study. In this paper, metrical characteristics of some English picture books were investigated, compared with English textbooks for Japanese junior high schools students. In short, frequency characteristics of character- and word-appearance were investigated. These characteristics were approximated by an exponential function. Furthermore, the percentage of Japanese junior high school required vocabulary and American basic vocabulary was calculated to obtain the difficulty-level. As a result, it was clearly shown that the English picture books have a similar tendency to literary writings in the characteristics of character-appearance, and some books are more difficult than English textbooks.
\end{abstract}

\section{CCS Concepts}

Information systems $\rightarrow$ Data management systems $\rightarrow$ Database design and models $\rightarrow$ Graph-based database models

\section{Keywords}

data mining; English text analysis; metrical linguistics; picture book; statistical analysis; text mining.

\section{INTRODUCTION}

A picture book plays an important role as a material to develop children's linguistic competence [7]. If a good picture book is read repeatedly in an exiting manner, a child unknowingly will pick up the beautiful language contained therein. He/she will begin to use the words and phrases in the book as his/her own, and repeat, imitate, and learn them as a part of his/her linguistic development [7]. This phenomenon occurs not only in Japanese, but also in English [8]. Thus, English picture books are useful in the acquisition of English-speaking skills and it is believed that they are indispensable to English learning for children [6].

In this study, metrical linguistic analysis of English picture books was conducted, so as to ascertain characteristics of writing styles used therein. English translation of the Miffy series by Dick Bruna was used as an example of English picture books. Types of characters and words, and their use frequency in the books were surveyed.

\footnotetext{
Permission to make digital or hard copies of all or part of this work for personal or classroom use is granted without fee provided that copies are not made or distributed for profit or commercial advantage and that copies bear this notice and the full citation on the first page. Copyrights for components of this work owned by others than ACM must be honored. Abstracting with credit is permitted. To copy otherwise, or republish, to post on servers or to redistribute to lists, requires prior specific permission and/or a fee. Request permissions from Permissions@acm.org.
}

ICVISP 2018, August 27-29, 2018, Las Vegas, NV, USA

(C) 2018 Association for Computing Machinery.

ACM ISBN 978-1-4503-6529-1/18/08 ..\$15.00

DOI: https://doi.org/10.1145/3271553.3271616

\section{METHOD OF ANALYSIS AND MATERIALS}

The materials analyzed here are as follows:

- Material 1: Miffy (1997, pub. World International, original pub. in Dutch 1963)

- Material 2: Miffy at the Zoo (1997, World International, 1963)

- Material 3: Miffy in the Snow (1997, World International, 1963)

- Material 4: Miffy at the Seaside (1997, World International, 1963)

- Material 5: Miffy Goes Flying (1997, World International, 1970)

- Material 6: Miffy's Birthday (1997, World International, 1970)

- Material 7: Miffy at the Playground (1997, World International, 1975)

- Material 8: Miffy in Hospital (1997, World International, 1975)

- Material 9: Miffy's Bicycle (1997, World International, 1982)

- Material 10: Miffy at School (1997, World International, 1984)

- Material 11:Miffy Goes to Stay (1997, World International, 1988)

- Material 12: Grandpa and Grandma Bunny (1998, World International, 1988)

- Material 13: Miffy is Crying (1997, World International, 1991)

- Material 14: Miffy's House (1998, World International, 1991)

- Material 15:Auntie Alice's Party (1998, World International, 1992)

- Material 16: Miffy in the Tent (1997, World International, 1995)

- Material 17:Dear Grandma Bunny (2005, EGMONT, 1996)

- Material 18: Miffy at the Gallery (1998, EGMONT, 1997)

- Material 19: Miffy and Melanie (2000, Kodansha International, 1999)

- Material 20:Miffy the Ghost (2003, Big Tent Entertainment, 2001)

- Material 21: Miffy the Fairy (2003, EGMONT, 2001)

- Material 22: Miffy Dances (2008, EGMONT, 2002)

- Material 23: Miffy and the New Baby (2005, EGMONT, 2003)

- Material 24: Miffy's Garden (2005, EGMONT, 2004)

All these materials were written by Dick Bruna (1927-2017) in Dutch in origin. They were translated into English by British literary translator Patricia Crampton (1927-2016).

For comparison, the contents of English textbooks $N E W$ HORIZON English Course 1, 2 and 3 (2009, Tokyo Shoseki Co., Ltd. (hereinafter referred to as "JHS 1, 2 and 3")), which are used in Japanese junior high schools, were also analyzed. 
The computer program for this analysis is composed of $\mathrm{C}++$. Besides the characteristics of character- and word-appearance for each piece of material, various information such as the "number of sentences," the "number of paragraphs," the "mean word length," the "number of words per sentence," etc. can be extracted by this program [1].

\section{RESULTS}

\subsection{Characteristics of Character-appearance}

First, the most frequently used characters in each material and their frequency were derived. In all of Materials 1-24 and all of the textbooks, the most frequently used character is blank, followed by "e." The third placed character is " $t$ " in 11 of the picture books, "a" in 10, "o" in two and " $h$ " in one, while in the textbooks it is "o" in two and "a" in one. In all materials, the characters "n," "i," "s" and "r" rank high, and the top 10 most frequent characters are almost identical in all materials, despite some variation in order.

The frequencies of the 50 most frequently used characters including the blanks, capitals, small letters and punctuations were plotted on a descending scale. The vertical shaft shows the degree of the frequency and the horizontal shaft shows the order of character-appearance. The vertical shaft is scaled with a logarithm. Figure 1 shows the results for Material 1.

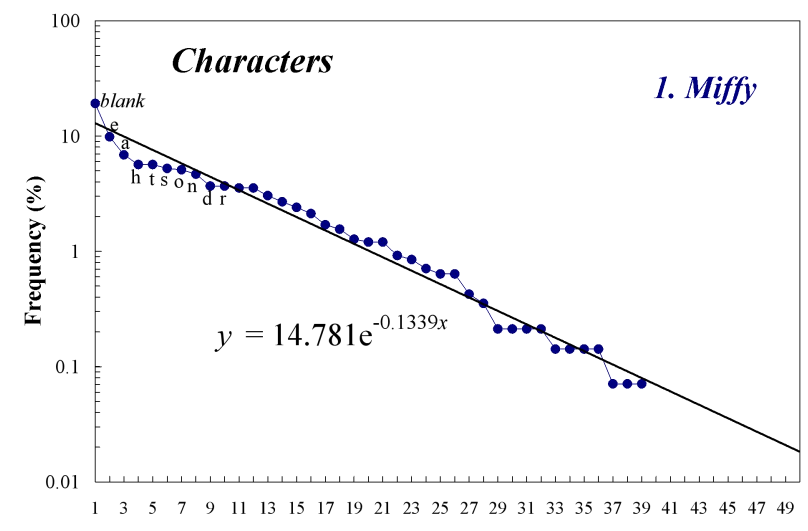

Order of appearance

Figure 1. Frequency characteristics of character-appearance in Material 1.

Between the 26th and 27th places, there is an inflection point caused by the difference in declines, and a relatively larger decline is observed at the 27 th place and thereafter. This characteristic curve was approximated by the following exponential function:

$$
y=c * \exp (-b x)
$$

From this function, coefficients $c$ and $b$ can be derived [3]. In the case of the Material 1, as shown in figure 1, the values $c=14.781$, $b=0.1339$ were obtained.

The distribution of coefficients $c$ and $b$ extracted from each material is shown in figure 2. There is a linear relationship between coefficients $c$ and $b$ for all materials, including textbooks. These values are approximated as $[y=0.007 x+0.0311]$ for the 24 picture book materials, and $[y=0.0115 x-0.0119]$ for the textbooks. Overall, the values for the picture books were higher, with $c$ at $10.525-17.349$, and $b$ at $0.1029-0.1541$, compared with $c$ at $8.799-10.194$, and $b$ at $0.0890-0.1052$ for the textbooks. Values rise for the textbooks as the academic year increases. Previously, various English writings were analyzed and it was reported that there is a positive correlation between the coefficients $c$ and $b$, and that the more journalistic the material is, the lower the values of $c$ and $b$ are, and the more literary, the higher the values of $c$ and $b$ [4]. The values of the coefficients for the 24 picture books are higher than those for the textbooks. Accordingly, it can be said that the picture books have a similar tendency to literary writings.

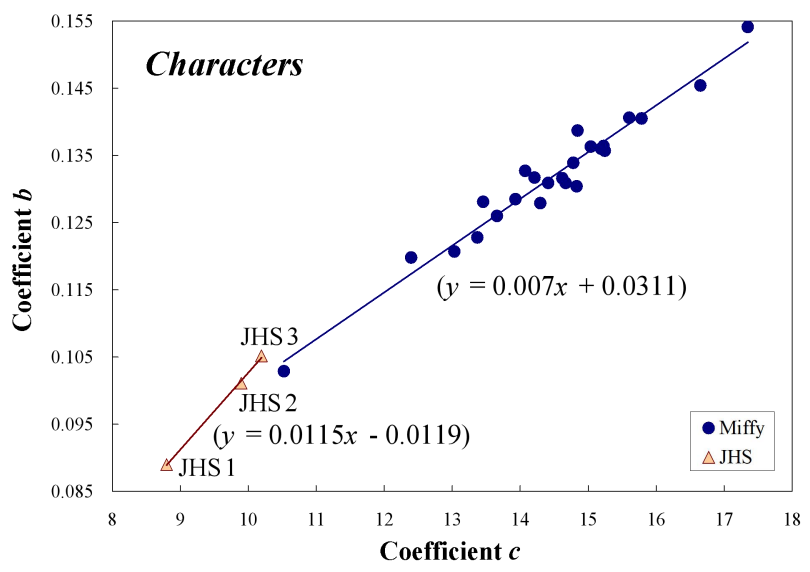

Figure 2. Dispersions of coefficients $c$ and $b$ for characterappearance.

\subsection{Characteristics of Word-appearance}

Next, frequency characteristics of word-appearance were derived. Table 1 shows the top 20 words most frequently used in six picture book examples - Materials 1, 5, 10, 15, 20 and 24 - and in the three textbooks. "And" is used extremely often used in the picture books, occupying first or second position in five materials except for Material 20. For this reason, "the," which occupies first or second position in the textbooks, comes in first to third position in the picture books. Furthermore, while the first and second person pronouns "I" and "you" occupy leading positions within the textbooks, in many of the picture books the third person pronouns "he," "she," "her" and "they" rank high. In addition to this, proper nouns such as" "Miffy" and "Alice," as well as past tense verbs such as "said," "cried" and "was" appear frequently.

Table 1. High-frequency words for each material.

\begin{tabular}{c||c|c|c|c|c|c|c|c:c}
\hline & Miffy 01 & Miffy 05 & Miffy 10 & Miffy 15 & Miffy 20 & Miffy 24 & JHS 1 & JHS 2 & JHS 3 \\
\hline 1 & and & and & the & the & a & to & I & the & the \\
2 & the & Miffy & and & and & Miffy & and & the & a & a \\
3 & a & the & a & a & the & the & you & I & to \\
4 & her & a & teacher & to & was & a & is & to & and \\
5 & to & look & they & said & you & her & a & you & you \\
6 & bunny & it & was & they & and & so & it's & and & in \\
7 & with & Miff & that & aunt & said & she & we & in & I \\
8 & all & uncle & to & her & aunt & carrots & I'm & it & is \\
9 & chicks & you & then & party & her & Miffy & to & is & of \\
10 & house & I & with & Alice & I & one & do & of & was \\
\hline 11 & Mrs & in & school & all & Alice & them & in & but & it \\
12 & said & said & all & danced & ghost & are & my & we & but \\
13 & she & see & her & for & mother & some & have & can & for \\
14 & was & cried & in & guests & sheet & up & yes & he & are \\
15 & baby & oh & said & you & to & very & are & was & she \\
16 & cow & was & she & but & Aggie & all & this & have & people \\
17 & have & what & so & come & how & bunny & at & for & this \\
18 & he & all & there & I'll & I'll & can & can & are & very \\
19 & so & flying & too & it & it & carrot & like & on & have \\
20 & they & just & up & on & like & father & and & about & my \\
\hline
\end{tabular}


Just as in the case of characters, the frequencies of the 50 most frequently used words in each material were plotted. Each characteristic curve was approximated by the same exponential function. The distribution of $c$ and $b$ is shown in figure 3 .

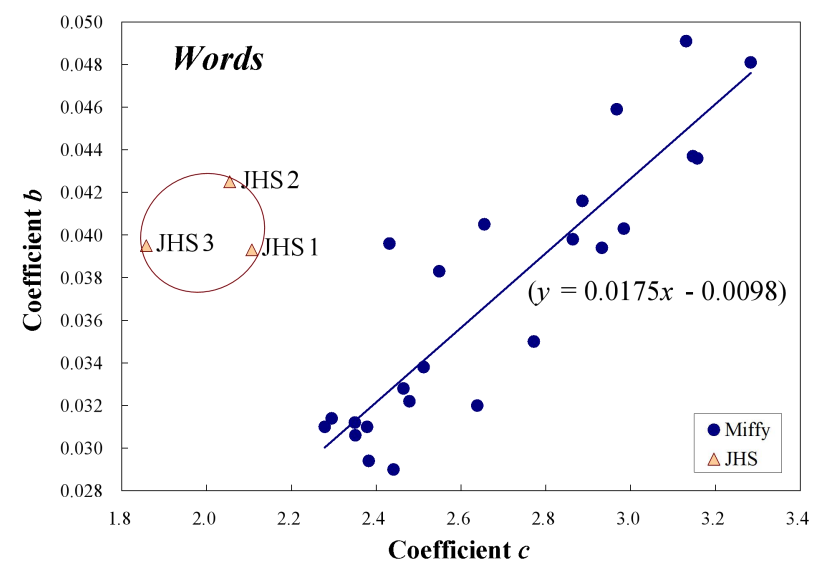

Figure 3. Dispersions of coefficients $c$ and $b$ for wordappearance.

The coefficient $c$ is $2.2786-3.2833$ for all 24 of the picture book materials, which is higher than that for the textbooks (1.8579 2.1067). From figure 3, a positive correlation between the coefficients $c$ and $b$, which is weaker than that for characters, is noted in the 24 picture book materials. These values are approximated by $[y=0.0175 x-0.0098]$. As for the coefficient $b$, it is roughly the same as the $0.0393-0.0425$ of the textbooks in six materials $(0.0394-0.0416)$, although 13 materials are lower $(0.0290-0.0383)$ and five are higher $(0.0436-0.0491)$. Thus, the values for a little more than half of the picture book materials are lower than those for the textbooks. On the other hand, the values for three textbook materials are relatively similar, and they might be regarded as a single cluster shown in figure 3 .

As a means to show the characteristics of words, statistician Udny Yule introduced an indicator called the " $K$-characteristic" in 1944 and made estimates with regard to the work The Imitation of Christ, using this indicator [9]. It can express the richness of vocabulary in writing by calculating the possibility of any randomly selected pair of words being identical. When a certain work contains $f_{i}$ pieces of words that are used $x_{i}$ times, assuming $S_{1}=\Sigma x_{i} f_{i}$ and $S_{2}=\Sigma x_{i}^{2} f_{i}$, the $K$-characteristic is defined as follows.

$$
K=10^{4}\left(S_{2} / S_{1}^{2}-1 / S_{1}\right)
$$

The $K$-characteristic for each material was examined. The results are shown in figure 4.

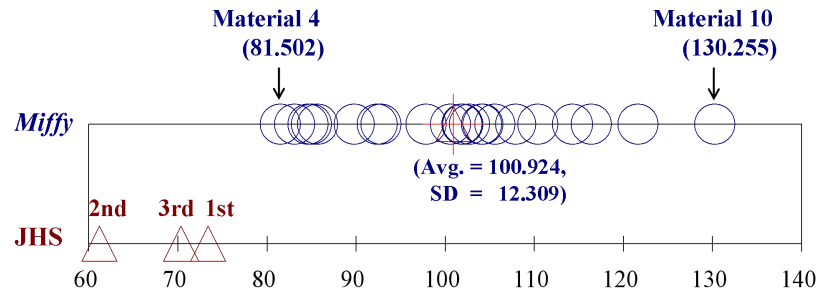

Figure 4. K-characteristic for each material.

From the figure, it can be seen that the $K$-value of the books ranges between 81.502 (Material 4) and 130.255 (Material 10), with a difference of roughly 50, but that all materials have higher values, compared with the three textbook materials (61.189 73.403). Of the picture books, 15 materials have a value over 100 , with the overall average value being 100.924, 32.6 higher than that of the textbooks, which averaged 68.317.

The characteristic of the values of picture books being higher than textbooks is the same as the cases of coefficients $c$ and $b$ for the frequency characteristics of character-appearance, and coefficient $c$ for that of word-appearance. Further investigation should be performed on the relationship between $K$-characteristic and the coefficients for character- and word-appearance in the future.

\subsection{Degree of Difficulty}

In order to show how difficult the materials are for readers, the degree of difficulty for each material through the variety of words and their frequency was derived [2]. As parameters for indicating difficulty, we considered difficulty level was considered based on the number of types of words used $\left(D_{w s}\right)$ and difficulty level based on the number of words used $\left(D_{w n}\right)$. As standard vocabulary, we used the 508 words that are required in the Japanese junior high school curriculum and 798 of the words contained in The American Heritage Picture Dictionary (American Heritage Dictionary, Houghton Mifflin, 2003) for four to eight-year old children in the United States (hereinafter the latter shall be referred to as "basic words"). Two types of difficulty levels $\left(D_{w s}\right.$ and $\left.D_{w n}\right)$ are obtained as follows, with the total number of words used as " $n_{t}$," the total number of types of words used as " $n_{s}$," the number of required/basic words as " $n_{r}$," and the number of required/basic words used as " $n(i)$."

$$
\begin{gathered}
D_{w s}=\left(1-n_{r s} / n_{s}\right) \\
D_{w n}=\left\{1-\left(1 / n_{t} * \sum n(i)\right)\right\}
\end{gathered}
$$

Thus, the values of both $D_{w s}$ and $D_{w n}$ were calculated, and it was shown that at which level of English the materials are, compared with other materials. Then, in order to obtain more appropriate indices, principal component analysis was conducted, considering $D_{w s}$ and $D_{w n}$ as variables.

$$
z=a_{1} * D_{w s}+a_{2} * D_{w n}
$$

where $a_{1}$ and $a_{2}$ are the weights used to combine $D_{w s}$ and $D_{w n}$. The first principal component $z$, obtained using the variancecovariance matrix, was indicated as $\left[z=0.7071 * D_{w s}+\right.$ $0.7071^{*} D_{w n}$ ] both for required words and basic words, from which the principal component scores were calculated. Figure 5 shows obtained principal component scores in one dimension.

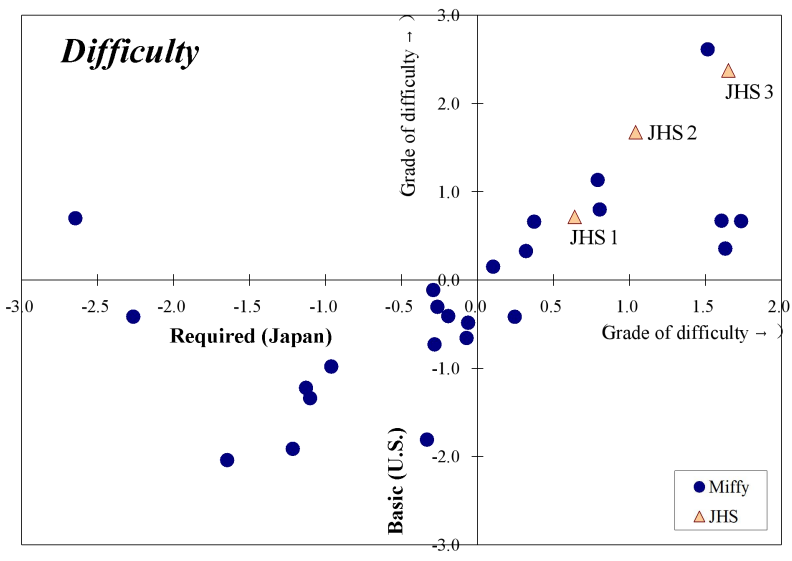

Figure 5. Principal component scores of difficulty. 
According to figure 5, as for both required and basic words, difficulty level of the textbook becomes higher as academic years progress, which shows the use of number of types and frequency of required and basic vocabulary is appropriate as parameters to estimate the level of difficulty. A weak positive correlation is observed between the difficulty level of required words and basic words for 24 picture book materials.

Judging from the required words, 18 materials are easier than the textbook for the first grade students. At the same time, two materials are more difficult than the first-grade textbook but easier than the second grade one, three are more difficult than the second grade textbook but easier than the third grade one, and one is more difficult than the third-grade textbook, giving an average level of difficulty for the picture books of -0.1389 .

With regard to the basic words, two materials are more difficult than the first grade textbook but easier than the second grade one, and one is more difficult than the third-grade textbook, with the remaining materials all easier than the first grade textbook, resulting in an average value of -0.1985 , which is slightly lower than that obtained using required words.

Overall, almost all the picture books are easier than the textbook for the first grade junior high school students, although a very small number of those are more difficult than the one for the third graders.

\subsection{Other Characteristics}

Other metrical characteristics of each material were examined. The results of the "average of word length," the "number of words per sentence," etc. are shown together in Table 2. The values shown for "Miffy" in the table are average values for the 24 picture book materials. Although the "frequency of prepositions," the "frequency of relatives," etc. were counted, some of the words counted might be used as other parts of speech because the meaning of each word was not checked.

Table 2. Metrical data for each material.

\begin{tabular}{l||c|c|c|c}
\hline & $\begin{array}{c}\text { Miffy } \\
\text { (Avg. of 24 materials) }\end{array}$ & $\begin{array}{c}\text { JHS 1 } \\
\text { (Horizon 1) }\end{array}$ & $\begin{array}{c}\text { JHS 2 } \\
\text { (Horizon 2) }\end{array}$ & $\begin{array}{c}\text { JHS 3 } \\
\text { (Horizon 3) }\end{array}$ \\
\hline Total num. of characters & 1,403 & 6,621 & 14,361 & 13,386 \\
Total num. of character-type & 41 & 68 & 69 & 71 \\
Total num. of words & 281 & 1,301 & 2,877 & 2,594 \\
Total num. of word-type & 151 & 481 & 800 & 764 \\
Total num. of sentences & 13 & 239 & 395 & 317 \\
Total num. of paragraphs & 12 & 218 & 226 & 176 \\
\hdashline Mean word length & 5.000 & 5.089 & 4.992 & 5.160 \\
Words/sentence & 23.982 & 5.444 & 7.284 & 8.183 \\
Sentences/paragraph & 1.052 & 1.096 & 1.748 & 1.801 \\
Repetition of a word & 1.857 & 2.705 & 3.596 & 3.395 \\
Commas/sentence & 1.710 & 0.272 & 0.223 & 0.331 \\
\hline Freq. of prepositions (\%) & 10.621 & 8.839 & 11.786 & 12.188 \\
Freq. of relatives (\%) & 2.963 & 1.768 & 1.392 & 1.927 \\
Freq. of auxiliaries (\%) & 1.687 & 0.923 & 1.529 & 1.119 \\
Freq. of personal pronouns (\%) & 12.503 & 17.758 & 15.503 & 12.496 \\
\hline
\end{tabular}

\subsubsection{Mean Word Length}

As for the "mean word length" for 24 picture book materials, the average value is 5.000 characters, which is almost the same as the shortest value among the junior high school textbooks, 4.992 characters, for the second year textbook. The shortest among the picture books is 4.716 characters. Three materials have average values slightly higher than the longest of the textbooks $(5.160$ characters), at 5.173, 5.177 and 5.412 characters.

\subsubsection{Number of Words Per Sentence}

The average of the "number of words per sentence" for picture books is 23.982 , which is 15.802 longer than the value for the third year textbook. Although the rage of the number of words for picture books is wide, 9.852 - 34.875 words, even the shortest is about 1.7 words longer than the third grade textbook at 8.1813 , and six materials have values of 29 words or more. Given this, it is considered that the Miffy series of English picture books is relatively difficult to comprehend.

\subsubsection{Number of Commas Per Sentence}

Due to the large number of words per sentence, the "number of commas per sentence" is also higher, at 1.710 than the textbooks at $0.223-0.331$.

\subsubsection{Frequency of Relatives}

The percentage of relatives includes that of relative pronouns, relative adverbs and relative adjectives. The average for picture books is $2.963 \%$, which is $1.0-1.5 \%$ higher than the textbooks at $1.392-1.927 \%$ in the textbooks. Therefore, it can be assumed that as the picture book materials tend to contain more complex sentences than textbooks, they are more difficult to read than textbooks.

\subsubsection{Frequency of Auxiliaries Frequency of Auxiliaries}

There are two kinds of auxiliaries in a broad sense. One expresses the tense and voice, such as $B E$ which makes up the progressive form and the passive form, the perfect tense $H A V E$, and $D O$ in interrogative sentences or negative sentences. The other is a modal auxiliary, such as WILL or CAN which expresses the mood or attitude of the speaker [5]. In this study, only modal auxiliaries were targeted.

As a result, the average of the "frequency of auxiliaries" is 1.687 $\%$ for picture books, which is $0.923-1.529 \%$ higher than that for textbooks. Although the range of values is $0.379-3.435 \%$, and the frequency for five materials $(0.379-0.840 \%)$ are lower than the lowest value among the textbooks $(0.923 \%)$, that for 12 materials $(1.749-3.435 \%)$ is higher than the highest value among the textbooks $1.529 \%$. Therefore, it might be said that while the writer of picture books tends to communicate his subtle thoughts and feelings with auxiliary verbs, the style of textbooks can be called more assertive.

\subsubsection{Word-length Distribution}

In addition, word-length distribution for each material was examined. The results are shown in figure 6 . The vertical shaft shows the degree of frequency with the word length as a variable. As for the 23 picture book materials except for Material 21, the frequency of 3- or 4-letter words is the highest: the frequency of 3-letter words ranges $18.919-36.975 \%$, and that of 4-letter words $19.485-31.081 \%$. Words consisting of 4 characters are the most frequent in all the textbooks, making up between 23.400 $-23.983 \%$, while there is a similar quantity of 3-letter words, at $21.061-23.566 \%$. In terms of 3- and 4-etter words in the picture books, the frequency of 3-letter words is higher than that of the textbooks in 18 materials, and that of 4-letter words higher than that of textbooks in 14 materials. At the same time, the textbooks contain a greater frequency of 6 - 9 character words than the picture books, which is considered to make mean word length for the textbooks slightly longer than that for picture books. 


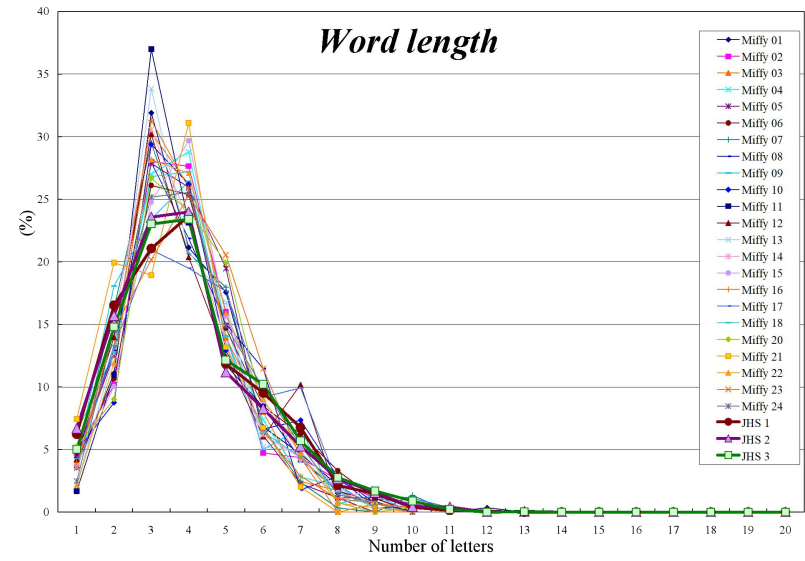

Figure 6. Word-length distribution for each material.

\subsubsection{Correlation of the Number of Words With That of Characters and Sentences}

Furthermore, the correlation between the "total number of words" and "total number of characters," as well as the correlation between the "total number of words" and "total number of sentences" was examined, in regard to the 24 picture book materials. Figure 7 shows the results, using the total number of words as a variable, while the total number of characters is in the vertical shaft, and the total number of sentences is used as the second vertical shaft.

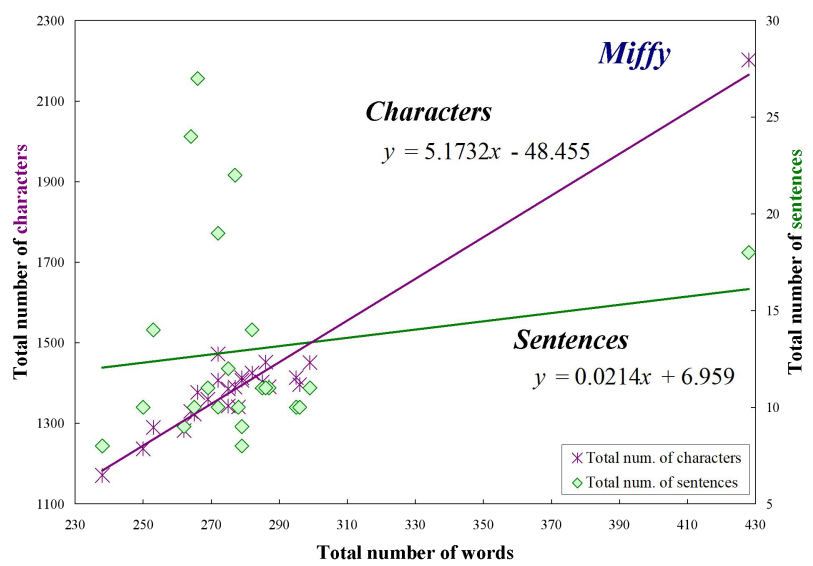

Figure 7. Correlation of the number of words with the number of characters and sentences.

From the figure, a strong positive correlation between the total number of words and the total number of characters, and a weak positive correlation between the total number of words and the total number of sentences can be seen. The approximation function shown in figure 7 is obtained for the values of the 24 materials. Accordingly, if the number of words in an English picture book from the Miffy series is known, then the function [ $y=$ $5.1732 x-48.455]$ can be applied to calculate its approximate total number of letters, and [ $y=0.0214 x+6.959]$ can be applied to calculate the approximate total number of sentences.

\subsection{Positioning of Each Material}

Based on the above results, principal component analysis being implemented using a correlation matrix, positioning of each material was established. The results are shown in figure 8.

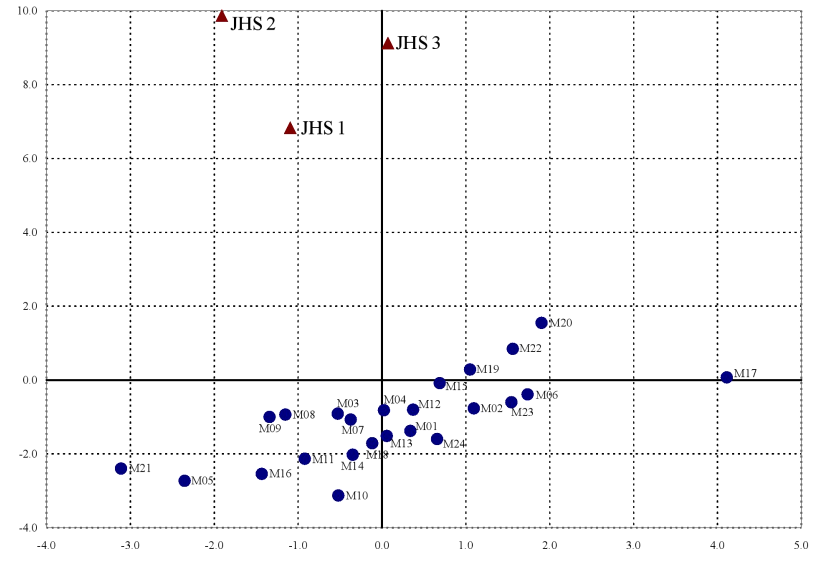

Figure 8. Positioning of each material.

According to figure 8, it can be seen that many of the books are positioned closely to the junior high school first year textbook. In terms of first principle component score, the 24 picture book materials and three textbook materials are close respectively. The textbooks score highly, at between 6.834 and 9.866, while four picture book materials $(17,19,20$ and 22$)$ are above 0 , with low scores ranging $0.069-1.546$. Therefore, the first principal component can be interpreted as the score indicating either the textbooks or the picture books. On the other hand, the score for the second principal component is above 0 in 13 of the picture book materials, and that of the textbooks is $-1.918,-1.094$ and 0.072 , two of which register below 0 .

\section{CONCLUSION}

The Miffy series of English picture books, as an example of English picture books, was analyzed metrically, in comparison with English textbooks for Japanese junior high school students, focused on the frequency characteristics of character- and wordappearance. An exponential approximation function was used to extract the characteristics of each material as to the coefficients $c$ and $b$. In addition, the $K$-characteristic value was calculated. Furthermore, the frequency of occurrence of the 508 required words for Japanese junior high school students and the 708 basic words used in America was examined, in order to calculate the level of difficulty. As a result, the frequency of characters in the picture books has the same tendency as that of literary works. The $K$-characteristic values are higher for picture books than they are for textbooks. Besides, in terms of level of difficulty, most of the picture books are easier than the junior high school first grade textbook, but there are some that are more difficult than the third grade textbook.

In the future, further extraction of characteristics of English picture books will be required, and it is anticipated that these results will be applied to studies in the field of infant English education.

\section{REFERENCES}

[1] Ban, H. and Oyabu, T. 2009. Metrical Analysis of the Speeches of 2008 American Presidential Election Candidates. In Proceedings of the 28th North American Fuzzy Information Processing Society Annual Conference, 5 pages.

[2] Ban, H., Dederick, T. and Oyabu, T. 2006. Metrical Linguistic Analysis of English Materials for Tourism. In Proceedings of the 7th Asia Pacific Industrial Engineering and Management Conference 2006, pp.1202-1208. 
[3] Ban, H., Nambo, H. and Oyabu, T. 2009. Linguistic Analysis of English Pamphlets at Local Airports in Japan. In Proceedings of the 20th National Conference of Australian Society for Operations Research incorporating the 5th International Intelligent Logistics System Conference, M2B, pp.4.1-4.9.

[4] Ban, H., Nambo, H. and Oyabu, T. 2008. Metrical Linguistic Characteristics of English Materials for Business Management. In Proceedings of the 3rd International Symposium on Computational Intelligence and Industrial Applications, 6 pages.

[5] Ban, H., Tabata, R., Hirano, K. and Oyabu, T. 2007. Linguistic Characteristics of English Articles on the Noto
Hanto Earthquake in 2007. In Proceedings of the 8th Asia Pacific Industrial Engineering \& Management System \& 2007 Chinese Institute of Industrial Engineers Conference, Paper ID: 905,7 pages.

[6] English textbooks used in Finland. http://www.kknews.co.jp/developer/finland/index.html.

[7] Regarding picture books. http://www.j-k-s.net/kosodate ehon.html.

[8] Tanaka, H. and Tanaka, S. 1996. Shakai Gengogaku e no Shoutai (Invitation to Sociolinguistics). Minervashobo, Kyoto.

[9] Yule, G. U. 1944. The Statistical Study of Literary Vocabulary. Cambridge University Press, Cambridge. 